\title{
Effect of Aerobic and Resistance Exercise Training on Liver Enzymes and Hepatic Fat in Iranian Men With Nonalcoholic Fatty Liver Disease
}

\author{
Alireza Shamsoddini, ${ }^{1}$ Vahid Sobhani, ${ }^{1}$ Mohammad Ebrahim Ghamar Chehreh, ${ }^{2}$ Seyed \\ Moayed Alavian,", and Ali Zaree \\ ${ }^{1}$ Exercise Physiology Research Center, Baqiyatallah University of Medical Sciences, Tehran, IR Iran \\ ${ }^{2}$ Baqiyatallah Research Center for Gastroenterology and Liver Diseases, Baqiyatallah University of Medical Sciences, Tehran, IR Iran \\ ${ }^{3}$ Department of Biochemistry, Baqiyatallah University of Medical Sciences, Tehran, IR Iran \\ *Corresponding Author: Seyed Moayed Alavian, Baqiyatallah Research Center for Gastroenterology and Liver Diseases, Baqiyatallah University of Medical Sciences, Tehran, IR Iran. \\ Tel:+98-2188945186, Fax:+98-2188945188, E-mail: alavian@thc.ir
}

Received 2015 July 11; Revised 2015 August 3; Accepted 2015 August 12.

\begin{abstract}
Background: Nonalcoholic fatty liver disease (NAFLD) has different prevalence rates in various parts of the world and is a risk factor for diabetes and cardiovascular disease that could progress to nonalcoholic steatohepatitis, cirrhosis, and liver failure.

Objectives: The current study aimed to investigate the effect of Aerobic Training (AT) and resistance training (RT) on hepatic fat content and liver enzyme levels in Iranian men.

Patients and Methods: In a randomized clinical trial study, 30 men with clinically defined NAFLD were allocated into three groups (aerobic, resistance and control). An aerobic group program consisted of 45 minutes of aerobic exercise at $60 \%$ - $75 \%$ maximum heart rate intensity, a resistance group performed seven resistance exercises at intensity of 50\%-70\% of 1 repetition maximum (1RM) and the control group had no exercise training program during the study. Before and after training, anthropometry, insulin sensitivity, liver enzymes and hepatic fat were elevated.

Results: After training, hepatic fat content was markedly reduced, to a similar extent, in both the aerobic and resistance exercise training groups $(\mathrm{P} \leq 0.05)$. In the two exercise training groups, alanine amino transferase and aspartate amino transferase serum levels were significantly decreased compared to the control group $(\mathrm{P}=0.002)$ and $(\mathrm{P}=0.02)$, respectively. Moreover, body fat $(\%)$, fat mass $(\mathrm{kg})$, homeostasis model assessment insulin resistance (HOMI-IR) were all improved in the AT and RT. These changes in the AT group were independent of weight loss.

Conclusions: This study demonstrated that RT and AT are equally effective in reducing hepatic fat content and liver enzyme levels among patients with NAFLD. However, aerobic exercise specifically improves NAFLD independent of any change in body weight.
\end{abstract}

Keywords: Exercise Trainig, Nonalcoholic Fatty Liver Disease, Resistance, Aerobic

\section{Background}

Nonalcoholic fatty liver disease (NAFLD) is the terminology used for a wide spectrum of disorders ranging from simple steatosis to progressive nonalcoholic steatohepatitis (NASH), hepatic fibrosis and cirrhosis and its diagnosis in clinics is based on ultrasonography (1, 2). Although, the actual prevalence of NAFLD remains unknown (3), the prevalence of NAFLD ranges from about $20 \%-35 \%$ in the Western population and about $19 \%$ - 32\% in Asian population (4), with the prevalence being higher (70\% - 90\%) in obese individuals (5). One study reported that the prevalence of NASH in Iranian males is twice than females (6). Nonalcoholic fatty liver disease is characterized by elevated liver enzymes including alanine amino transferase (ALT) and aspartate amino transferase (AST) and also, build-up of fat within liver cells (7). Obesity, sedentary lifestyle and insulin resistance are well-established risk factors for NAFLD; however, the pathogenesis of NAFLD is incompletely understood and factors that determine disease severity remain unclear (8). Although, the severity of fatty liver was positively related to anthropometric measurements including body mass index (BMI), waist and hip circumference, subcutaneous adipose tissue thickness and hypertriglyceridaemia (3, 9) Currently, there is no specific drug therapy approved for the treatment of NAFLD and management focus on treatment of the "metabolic syndrome" rather than NAFLD as an individual entity (10). Lifestyle change and Physical Activities are currently the main recommendation for people with NAFLD. Lifestyle interventions in the form of calorie restriction and increasing the physical activity level with an aim to reduce weight remain the cornerstone

Copyright (C) 2015, Kowsar Corp. This is an open-access article distributed under the terms of the Creative Commons Attribution-NonCommercial 4.0 International License (http://creativecommons.org/licenses/by-nc/4.0/) which permits copy and redistribute the material just in noncommercial usages, provided the original work is properly cited. 
of treatment for patients with NAFLD (11). Exercise training (ET) is a major component of treatment for NAFLD (8) as recommended by the American Gastroenterological Association (12). However, the role of ET in the treatment of this condition has not been thoroughly investigated and only few studies have investigated the effect of ET on NAFLD, usually in combination with diet and weight loss (4,13-18). Exercise training has been shown to reduce the risk of insulin resistance, aminotransferase levels, dyslipidemia, and impaired fasting glucose and can be beneficial for glucose-lipid metabolism ( 8 , 19). Aerobic and resistance exercise can be therapeutic in reducing liver fat deposition by increasing energy expenditure, improvement in skeletal lipid oxidation, reduction in total and abdominal adiposity, reduction in subcutaneous fat and free fatty acid flux to liver $(4,14$, 19-21). Overall, there is very limited data on the effectiveness of aerobic and resistance exercise on hepatic function in NAFLD. Mir et al. (17) demonstrated a significant reduction in aminotransferase levels and liver fat in patients with NASH who adhered to an aerobic exercise program. The results of one study demonstrated that, short-term exercise can target hepatic lipid composition, which may reduce the risk of NAFLD progression (16). de Piano et al. (15) present that the long-term exercise therapy along with aerobic and resistance therapy was significantly effective in improving noninvasive biomarkers of NAFLD. In another study, Damor et al. (4) present that moderate intensity progress resistance training is associated with significant improvement in hepatic fat, subcutaneous fat and insulin sensitivity in patients with NAFLD. Davoodi et al. (14) evaluated the effects of aerobic exercise on liver enzymes and hepatic fat in subjects with NAFLD. They reported that after eight weeks, aminotransferase levels and hepatic fat were significantly reduced in the aerobic group. So far, to the best of our knowledge, there are no data on the effect of aerobic and resistance exercise on liver aminotransferase levels and hepatic fat among the Iranian men with NAFLD; therefore, this study was undertaken.

\section{Objectives}

The present study was conducted to examine the effect of aerobic and resistance exercise training on liver enzymes and hepatic fat in men with NAFLD in Iran.

\section{Patients and Methods}

\subsection{Subjects}

In this randomized clinical trial study, subjects were randomly selected from the liver clinic in the department of gastroenterology/hepatology at Baqiyatallah Hospital in Tehran City, Iran. Sample size estimation was performed through single proportion formula with 95\% confidence interval and the calculated sample size was 30. Subjects were between 32 and 54 years of age. Inclusion criteria including men with hepatic steatosis, which was confirmed by ultrasonography with acceptable sensitivity and specificity and was based on a hepatic triglyceride content greater than 5\% (22). Exclusion criteria were identified as genetic, metabolic or endocrine diseases (15), alcohol consumption $\geq 30$ g/day (13), heart and pulmonary disease, patients with chronic hepatitis B and C, autoimmune hepatitis, drug abuse, and patients with diabetic mellitus and fasting hyperglycemia. The study protocol was approved by the human research ethics committees of the Baqiyatallah University of Medical Sciences (January 5, 2014 with Code No: 34). An informed consent was obtained from all patients, including agreement of the patients to participate as volunteers. The patients were then divided into three equal groups, aerobic, resistance and control groups ( $\mathrm{n}=10$ in each group).

\subsection{Aerobic Exercise Intervention}

During the 8 week intervention period, an aerobic training (AT) program including a 45 minute session three times a week (135 min/week) under the supervision of an exercise physiologist and sport medicine. Aerobic exercise consists of three phases: warm-up, training and cool down. At the beginning of exercise session, subjects had a ten minute warm-up. The warmup protocol was consisted of stretching movements and slowly running on treadmill. Then, the warm-up phase was followed by the training phase. At baseline, the training phase commenced with two 15 minute running on treadmill at $60 \%$ of their maximal heart rate (MHR) in the first week and increased to two 15 minute running on treadmill at $75 \%$ MHR per week by the final week of training (23). To assure that the desired heart rate (exercise intensity) was achieved and maintained for 30 minute, during the aerobic sessions, each participant underwent heart-rate monitoring with polar (model: FT1) heart rate monitor (24). Maximum heart rate was calculated using the formula (25):

$$
\mathrm{HR}_{\mathrm{Max}}=\text { age }-220
$$

\subsection{Resistance Exercise Intervention}

Resistance training was performed during 8-weeks with thrice weekly sessions on nonconsecutive days. The program consisted of seven exercises: triceps press, biceps curl, calf raise, leg press, leg extension, lat pull down and sit-ups (21). Each session lasted approximately 45 minute and consisted of a 5 minute warm-up with stretching followed by resistance exercise done as a circuit, ending with 5 minute cool down. The 1 repetition maximum (1RM) was measured at baseline and following the intervention (26). Initially, participants did two 
circuits using 50\% of their $1 \mathrm{RM}$ and repeated them 10 times for the first and second weeks, progressing to two circuits, using $60 \%$ of their $1 \mathrm{RM}$ and repeated 10 times for the third and fourth weeks. In fifth and sixth weeks, participants did three circuits using $60 \%$ of their 1RM and repeated 10 times. In the last two weeks, patients did three circuits using 70\% of their 1RM and repeated 10 times (27). A 90-second rest was allowed between sets of exercises.

\subsection{Anthropometric Measurements and Body Composition}

At three preliminary sessions, subjects came to the laboratory to familiarize with the training equipment and procedure. Then, anthropometric components and body composition elements of any patient were determined in the start and the end of the study. Height was measured to the nearest $0.5 \mathrm{~cm}$ using a wall-mounted stadiometer. Waist circumference and hip circumference were measured to the nearest $0.5 \mathrm{~cm}$ with a nonelastic tape measure. To calculate the subcutaneous fat, the pectoral, abdominal and thigh skin fold were measured using the slim guide skin fold caliper (Model: AC-6575) on the dominant side of the body (28). Also, fat mass of whole body, BMI and weight of any patient were determined using the body composition analyzer (Model: Tanita, BC-418).

\subsection{Testing and Outcome Variables}

Subjects did not perform any exercise 48 hour before testing and were on 12 hours fasting prior to testing. Blood samples were taken from the antecubital vein and collected in heparinized tubes and analyzed for liver enzymes (ALT and AST) or frozen and stored at $-70^{\circ} \mathrm{C}$ for subsequent analysis of plasma glucose and insulin. The ALT and AST enzymes' levels were measured by Biosystem kits (Biosystem S.A., Barcelona, Spain) and through the spectrophotometry method (29). Sonography was used to measure liver fat and performed by one radiologist in all subjects with the same equipment at Baqiyatallah Hospital. Fatty liver was diagnosed via abdominal ultrasonography (US) using standardized criteria (30). Liver steatosis that detected by liver sonography was graded from 0 to 3. Grade 0 (no steatosis), grade one (mild) slightly increased echogenicity, grade two (moderate) moderately increased echogenicity and grade three (severe) markedly increased echogenicity (31). Following the 8-week exercise training intervention, subjects repeated the same tests in the same manner and order. To prevent the acute effects of exercise training altering posttraining test results, post-testing was performed 72 hours after stopping exercise (32).

\subsection{Determination of the Homeostasis Model As- sessment of Insulin Resistance}

Fasting glucose level was measured using the GOD-
PAP method (Biosystems S.A. Barcelona, Spain), which is an enzyme colorometric test without deproteinization. Moreover, the fasting insulin level was measured using a chemiluminescent immunoassay (LIAISON® Insulin assay, DiaSorin, Saluggia, Italy), and samples were analyzed on the LIAISON® Analyzer (DiaSorin). The homeostasis model assessment of insulin resistance (HOMA-IR), a measure of insulin resistance, was determined according to the following equation (33):

$$
\mathrm{HOMA}-\mathrm{IR}=\frac{\text { insulin }\left(\frac{\mathrm{mIU}}{L}\right) \times \text { glucose }\left(\frac{\mathrm{mmol}}{\mathrm{L}}\right)}{22.5}
$$

\subsection{Control Group}

The control group had no exercise training program during the 8-week period of the study. However, the daily physical activity was performed. In this group, studied parameters were evaluated, as well as other groups.

\subsection{Statistical Analysis}

Analysis of Variance (ANOVA) was used to identify between-group differences. When significance occurred, a Tukey's honestly significant difference (HSD) post-hoc test was used to determine the source of the difference. The changes within each group were undertaken using paired t-tests. Statistical significance was accepted when $\mathrm{P}<0.05$. Moreover, SPSS software version 18.0 (SPSS, Inc. Chicago, Illinois, USA) was used for data analysis.

\section{Results}

An informed consent was obtained from 30 patients and they were enrolled in the study. Table 1 shows anthropometric and body composition data of subjects with NAFLD before and after interventions. It was observed that aerobic and resistance groups presented significant improvement for anthropometric parameters. However, weight $(\mathrm{kg})$ and BMI $\left(\mathrm{kg} / \mathrm{m}^{2}\right)$ were improved significantly only in the resistance exercise group. Repeated measure ANOVA analyses showed a significant difference regarding mean ALT, AST changes between the groups (Table 2). Post-hoc analyses showed significant differences in ALT, AST and hepatic fat between the control and aerobic groups, and the control and resistance groups (Table 3). Basal fatty liver that was diagnosed by sonography, after intervention, was significantly decreased in the aerobic and resistance exercise groups. However, in the control group, the liver fat content was slightly increased after 8weeks (Figure 1). Moreover, after training intervention, the aerobic group only presented significantly lower values of HOMA-IR compared to the control group (Figure 2). 
Shamsoddini A et al.

Table 1. Total Body Fat, Fat Mass, Body Mass Index, Waist and Hip Circumference and Subcutaneous Body Fat Changes Observed After an Eight-Week Training Intervention in Three Groups ${ }^{\mathrm{a}, \mathrm{b}}$

\begin{tabular}{|c|c|c|c|c|c|c|c|c|c|}
\hline \multirow{2}{*}{ Variables } & \multicolumn{3}{|c|}{ Control } & \multicolumn{3}{|c|}{ Aerobic } & \multicolumn{3}{|c|}{ Resistance } \\
\hline & Baseline & Posttest & P Value & Baseline & Posttest & PValue & Baseline & Posttest & PValue \\
\hline Age, $y$ & $45.8 \pm 7.3$ & - & - & $39.7 \pm 6.3$ & - & - & $45.9 \pm 7.3$ & - & - \\
\hline \multicolumn{10}{|c|}{ Anthropometry } \\
\hline Height, cm & $172 \pm 4.4$ & - & - & $174.8 \pm 2.8$ & - & - & $174.9 \pm 7.8$ & - & - \\
\hline Weight, kg & $82.2 \pm 10.8$ & $81.5 \pm 11.1$ & 0.05 & $85.7 \pm 10.1$ & $83.9 \pm 11.7$ & 0.15 & $94.3 \pm 16.3$ & $92.2 \pm 16.1$ & 0.01 \\
\hline BMI, $\mathrm{kg} / \mathrm{m}^{2}$ & $28.2 \pm 3.7$ & $27.5 \pm 3.9$ & 0.16 & $28.1 \pm 3.1$ & $27.5 \pm 3.5$ & 0.14 & $30.6 \pm 2.6$ & $29.9 \pm 2.6$ & 0.03 \\
\hline Body fat, \% & $23.3 \pm 6$ & $23.2 \pm 5.8$ & 0.49 & $21.3 \pm 4.6$ & $20 \pm 5.2$ & 0.009 & $25.6 \pm 4.4$ & $24.6 \pm 4.2$ & 0.002 \\
\hline Fat mass, kg & $19.6 \pm 6.6$ & $19.5 \pm 6.1$ & 0.70 & $18.4 \pm 5.6$ & $17.1 \pm 5.7$ & 0.01 & $20.6 \pm 6.6$ & $19.9 \pm 6.5$ & 0.002 \\
\hline \multicolumn{10}{|c|}{ Circumference, cm } \\
\hline Waist & $97.6 \pm 8.1$ & $95.5 \pm 7.9$ & 0.02 & $98.5 \pm 7.8$ & $94.6 \pm 7.7$ & 0.000 & $108.6 \pm 7.8$ & $103.2 \pm 6.3$ & 0.001 \\
\hline Hip & $102.4 \pm 5.9$ & $102.1 \pm 6.2$ & 0.74 & $105.8 \pm 5.4$ & $100.7 \pm 4.6$ & 0.000 & $107.9 \pm 7$ & $105.8 \pm 6.1$ & 0.03 \\
\hline \multicolumn{10}{|c|}{$\begin{array}{l}\text { Subcutaneous } \\
\text { body fat, mm }\end{array}$} \\
\hline Abdominal & $38.1 \pm 8.3$ & $37 \pm 7.6$ & 0.47 & $42.2 \pm 12.3$ & $37.6 \pm 9.7$ & 0.07 & $45.2 \pm 13.2$ & $39.1 \pm 9.1$ & 0.03 \\
\hline Pectoral & $23.2 \pm 8.4$ & $23.3 \pm 8.6$ & 0.78 & $25.1 \pm 9.7$ & $22.6 \pm 7$ & 0.20 & $25 \pm 8.4$ & $25 \pm 8.5$ & 1.0 \\
\hline Thigh & $29.7 \pm 9.8$ & $29 \pm 7.1$ & 0.65 & $27.4 \pm 8.8$ & $26.8 \pm 7.3$ & 0.56 & $29.4 \pm 7.5$ & $31.2 \pm 8.60$ & 0.21 \\
\hline
\end{tabular}

a Abbreviation: BMI, body mass index.

Values are presented as Mean \pm SD.

\begin{tabular}{|c|c|c|c|c|c|c|c|c|c|c|}
\hline \multirow{2}{*}{ Variable } & \multicolumn{3}{|c|}{ Control } & \multicolumn{3}{|c|}{ Aerobic } & \multicolumn{3}{|c|}{ Resistance } & \multirow{2}{*}{ P Value } \\
\hline & baseline & Posttest & $\Delta$ & baseline & Posttest & $\Delta$ & baseline & Posttest & $\Delta$ & \\
\hline $\operatorname{ALT}(\mathbf{U} / \mathbf{L})$ & $48.3 \pm 17.6$ & $\begin{array}{c}49.6 \pm \\
17.6\end{array}$ & $1.3 \pm 4$ & $\begin{array}{c}36.9 \pm \\
16.4\end{array}$ & $24.4 \pm 7,2$ & $-12.5 \pm 11.1$ & $56 \pm 23.7$ & $41.3 \pm 19.5$ & $-14.7 \pm 12.2$ & 0.002 \\
\hline $\operatorname{AST}(\mathbf{U} / \mathbf{L})$ & $32 \pm 7.1$ & $31.6 \pm 7.6$ & $-0.4 \pm 5.1$ & $29.7 \pm 9$ & $20.9 \pm 4.4$ & $-8.8 \pm 7.3$ & $\begin{array}{c}39.8 \pm \\
21.19\end{array}$ & $34.7 \pm 18.1$ & $-5.1 \pm 6.8$ & 0.02 \\
\hline $\operatorname{ALP}(\mathbf{U} / \mathbf{L})$ & $\begin{array}{c}189.4 \pm \\
42.3\end{array}$ & $184.3 \pm 34$ & $-5.1 \pm 14.2$ & $\begin{array}{c}165.5 \pm \\
48.1\end{array}$ & $\begin{array}{c}139.1 \pm \\
35.7\end{array}$ & $\begin{array}{c}-26.4 \pm \\
30.1\end{array}$ & $\begin{array}{c}186.3 \pm \\
41.1\end{array}$ & $\begin{array}{c}161.3 \pm \\
39.4\end{array}$ & $-25 \pm 31.2$ & 0.15 \\
\hline
\end{tabular}

a Abbreviations: $\Delta, \Delta$ is differences between post and baseline (mean of changes); ALT, alanine transaminase; ALP, alkaline phosphatase; AST, aspartate transaminase.

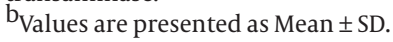

\begin{tabular}{|c|c|c|c|c|c|c|}
\hline \multirow{2}{*}{ Group } & \multicolumn{2}{|l|}{ ALT } & \multicolumn{2}{|l|}{ AST } & \multicolumn{2}{|c|}{ Hepatic Fat } \\
\hline & Mean Differences & PValue & Mean Differences & PValue & Mean Differences & P Value \\
\hline $\begin{array}{l}\text { Control group } \\
\text { comparisons with } \\
\text { aerobic }\end{array}$ & 13.8 & 0.01 & 8.4 & 0.02 & 1.1 & 0.004 \\
\hline $\begin{array}{l}\text { Control group } \\
\text { comparisons with } \\
\text { resistance }\end{array}$ & 16 & 0.003 & 5.9 & 0.04 & 0.8 & 0.03 \\
\hline $\begin{array}{l}\text { Resistance group } \\
\text { comparisons with } \\
\text { aerobic }\end{array}$ & 3.2 & 0.87 & 3.7 & 0.42 & 0.3 & 0.6 \\
\hline
\end{tabular}

abbreviations: ALT, alanine amino transferase; AST, aspartate amino transferase. 
Shamsoddini A et al.

Figure 1. Hepatic Fat in Three Groups Before and After an Eight-Week Intervention

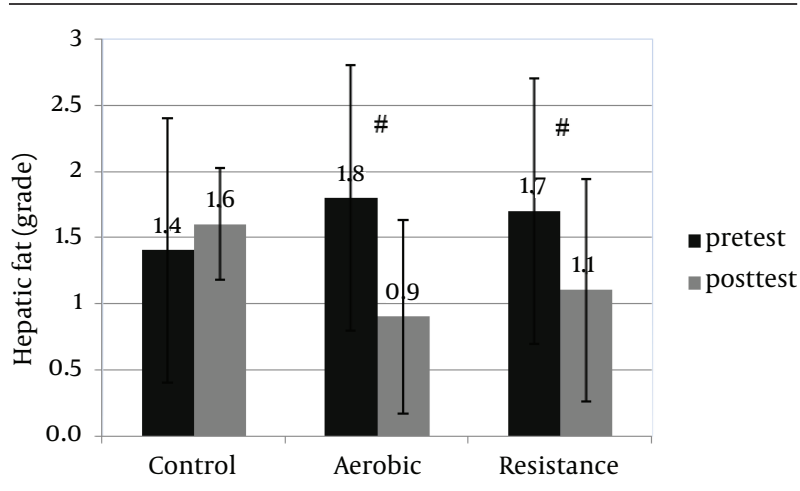

Data are presented as Mean $\pm \mathrm{SD}$; \#, indicats $\mathrm{P}<0.05$ is significant.

Figure 2. Effects of Exercise Mode(s) (Aerobic Training, Resistance Training) and Control Group on Changes in Homeostasis Model Assessment of Insulin Resistance

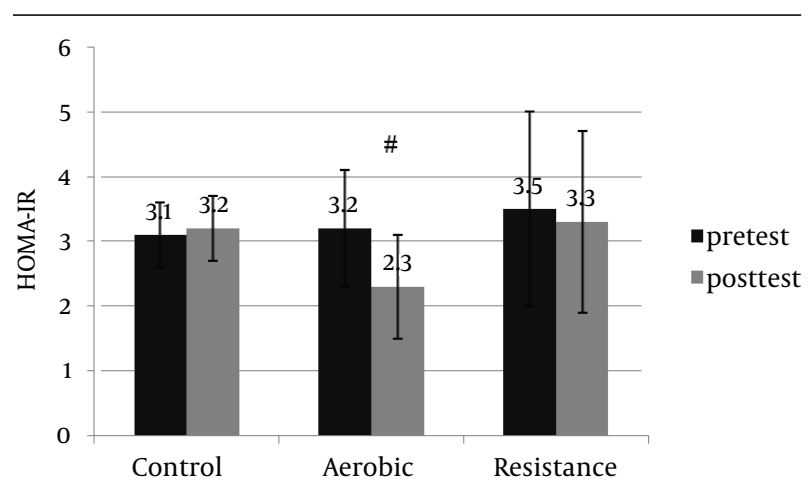

Data are presented as Mean $\pm \mathrm{SD}$; \#, indicats $\mathrm{P}<0.05$ is significant.

\section{Discussion}

For some time we have been interested in how much exercise training, what types (modes) of exercise and what exercise intensity are most beneficial for peoples with NAFLD. Although, it is a fact that not any one amount or type of exercise is likely to be best for patients with NAFLD (34). In this study, we compare the effects of aerobic and resistance exercise on hepatic fat and liver enzymes in peoples with NAFLD. Because, it is important for the clinician to understand whether resistance or aerobic training is superior in inducing changes in hepatic fat liver enzymes and body composition in individuals with NAFLD. An 8-week aerobic and resistance exercise program brought about a significantly reduction in liver fat and improving in fasting insulin resistance (HOMA). This was accompanied by a significantly increase in insulin sensitivity, and decreased ALT and AST levels after aerobic exercise in the absence of any change in body weight. Although in the resistance group, these changes were associated with a significant reduction in body weight and BMI. Our findings are consistent with previous studies that observed a decrease in hepatic fat following aerobic exercise in people with NAFLD. Davoodi et al. (14) demonstrated that hepatic fat and the serum AST and ALT levels were reduced after 8 weeks aerobic exercise. van der Heijden et al.(35) demonstrated that a 12-week aerobic exercise program without weight loss or change in BMI, results in reduced visceral and hepatic fat content, and decreased insulin resistance in obese adolescents. Chen et al. (36) in their study showed that insulin resistance and hepatic fat were significantly decreased after a 10-week aerobic exercise. Haus et al. (16) reported aerobic exercise can target hepatic fat, which may reduce the risk of NAFLD progression. They have suggested that the improvement in hepatic lipid composition may be driven by adiponectin, fat oxidation and increase on insulin sensitivity. Hallsworth et al. (21) expressed that the mechanisms underlying the change in hepatic fat following exercise training are likely to reflect changes in insulin sensitivity, circulatory lipids and energy balance. Insulin sensitivity plays a significant role in internal hepatic lipid homeostasis. Our findings would support other reports that exercise training increases body glucose disposal at least partly due to increases expression of GLUT4 in skeletal muscles, insulin receptor and glycogen storage (37). Also, moderate to vigorous exercise training increases fatty acid oxidation from adipose, intramyocellular, and possibly hepatic sources (38). Contrary to our results about the resistance group, Hallsworth et al. (21) reported that an 8-week resistance exercise program improves NAFLD (reduction in liver lipid and HOMA-IR) independent of any change in body weight. In this study, we found significant reductions in ALT and AST levels, independent of weight loss, after 8weeks of aerobic exercise in men with NAFLD. Although in resistance training, reduction in ALT and AST were dependent to weight loss and decrease in BMI. Similar findings have been reported previously about the relation between aerobic exercise training with ALT and AST (17) and also physical activity and ALT in NAFLD (32). Although limited number of studies have explored the role of aerobic and resistance exercises on ALT and AST levels in patients with NAFLD. de Piano et al. (15) compared the effectiveness of resistance and aerobic (AT + RT) with aerobic exercise in obese adolescents with NAFLD. In those who underwent resistance and aerobic exercise, presented lower ALT after intervention compared with aerobic training. Sreenivasa Baba et al. (19) also, reported that moderate intensity aerobic exercise helps in normalizing ALT levels in patients with NAFLD. Comparisons between aerobic and resistance training groups in the current study suggest that resistance training decreases both body weight and BMI significantly more than aerobic training. The lack of body mass loss observed with aerobic training in this study supports the findings of others and is likely driven by an increase in lean body mass (39-41). Finally, this study demonstrated that 8 weeks of exercise training favorably decreases abdominal obesity (as measured by waist circumference), body fat and fat mass and greatly improves hip circumference and abdominal subcutane- 
ous fat in aerobic and resistance groups. Surprisingly, however, other markers of adiposity, such as pectoral and thigh subcutaneous fat were unaltered at the end of the study. In one study, Bell et al. reported that an 8-week combined aerobic and resistance exercise program without weight loss resulted in decreased insulin resistance and reduced waist circumference in sedentary obese individuals (42). Also, with regard to body composition, Gutin and Owens observed that a 12-week aerobic exercise program attenuated growth-related increase in abdominal subcutaneous fat and visceral fat accumulation compared to the control group (43). In another study, Gutin et al. (44) demonstrated that an 8-month program of physical activity combined with lifestyle education decreased abdominal subcutaneous fat and visceral fat content. Both study results are in line with our findings. Our results indicate that aerobic exercise without weight loss results in decreased abdominal subcutaneous fat and visceral fat content but not pectoral and thigh subcutaneous fat. We postulate that this is due to the fact that abdominal subcutaneous and visceral fat is more metabolically active $(35,45)$.

Our study has three limitations. First, the small size of patients can be considered as a limitation of study. Undoubtedly, study of broader spectrum of NAFLD patients is necessary to increase the external validity of our findings. Second, in the present study, NAFLD was not diagnosed based on histology; so, the fat content was not measured bybiopsy. Third, an important limitation of this study is that hepatic fat measures obtained from US, similar to other reports $(46,47)$, while highly correlated to liver fat measures from Magnetic Resonance Spectroscopy (MRS) and liver biopsy studies $(48,49)$ are not direct measures of liver fat. However, the changes in hepatic fat are very similar to the patterns of change across the two exercise groups in ALT, AST, waist and hip circumference, abdominal subcutaneous fat and HOMA-IR. In conclusion, the results of this randomized controlled trial demonstrate that 8 weeks of aerobic training and resistance training are equally effective in reducing hepatic fat content and liver enzymes levels (ALT and AST) in patients with NAFLD. Interestingly, in the aerobic group, these changes are independent of weight loss and decrease of BMI. Our data indicate that exercise training (aerobic and resistance) can provide benefit for the management of NAFLD.

\section{Acknowledgments}

This study was jointly supported by exercise physiology research center and research center for gastroenterology and liver disease in Baqiyatallah University of Medical Sciences, Tehran, Iran. Also, we would like to thank staff of the laboratory of Baqiyatallah Hospital for sample gathering.

\section{Footnotes}

Authors' Contributions: Vahid Sobhani, Mohammad Ebrahim Ghamar Chehreh, Seyed Moayed Alavian, Alireza Shamsoddini: Study concept and design. Alireza Sham- soddini, Vahid Sobhani, Mohammad Ebrahim Ghamar Chehreh, Ali Zaree: Acquisition of data. Alireza Shamsoddini, Mohammad Ebrahim Ghamar Chehreh, Vahid Sobhani, Ali Zaree: Analysis and interpretation of data. Alireza Shamsoddini, and Seyed Moayed Alavian: Drafting of the manuscript. Alireza Shamsoddini, and Seyed Moayed Alavian: Editing of the manuscript.

Funding/Support: This study was supported by exercise physiology research center and research center for gastroenterology and liver disease in Baqiyatallah University of Medical Sciences, Tehran, IR Iran.

\section{References}

1. Ghamar-Chehreh ME, Khedmat H, Amini M, Taheri S. Predictive factors for ultrasonographic grading of nonalcoholic Fatty liver disease. Hepat Mon. 2012;12(11):e6860. doi: 10.5812/hepatmon.6860. [PubMed: 23346150]

2. Khedmat H, Taheri S. Non-alcoholic steatohepatitis: An update in pathophysiology, diagnosis and therapy. Hepat Mon. 2011;11(2):74-85.

3. Alavian SM, Mohammad-Alizadeh AH, Esna-Ashari F, Ardalan $G$, Hajarizadeh B. Non-alcoholic fatty liver disease prevalence among school-aged children and adolescents in Iran and its association with biochemical and anthropometric measures. Liver Int. 2009;29(2):159-63. doi: 10.1111/j.1478-3231.2008.01790.x. [PubMed: 18492015]

4. Damor K, Mittal K, Bhalla AS, Sood R, Pandey RM, Guleria R, et al. Effect of Progressive Resistance Exercise Training on Hepatic Fat in Asian Indians with Non-Alcoholic Fatty Liver Disease. British J Med Med Res. 2014;4(1):114-24

5. Chitturi S, Wong VW, Farrell G. Nonalcoholic fatty liver in Asia: Firmly entrenched and rapidly gaining ground. J Gas troenterol Hepatol. 2011;26 Suppl 1:163-72. doi: 10.1111/j.1440 1746.2010.06548.x. [PubMed: 21199528]

6. Sohrabpour A, Rezvan H, Amini-Kafiabad S, Dayhim M, Merat S, Pourshams A. Prevalence of Nonalcoholic Steatohepatitis in Iran: A Population based Study. Middle East J Dig Dis. 2010;2(1):149. [PubMed: 25197507]

7. St George A, Bauman A, Johnston A, Farrell G, Chey T, George J. Independent effects of physical activity in patients with nonalcoholic fatty liver disease. Hepatology. 2009;50(1):68-76. doi: 10.1002/hep.22940. [PubMed: 19444870]

8. Kistler KD, Brunt EM, Clark JM, Diehl AM, Sallis JF, Schwimmer JB, et al. Physical activity recommendations, exercise intensity, and histological severity of nonalcoholic fatty liver disease. Am J Gastroenterol.2011;106(3):460-8. doi:10.1038/ajg.2010.488.[PubMed: 21206486]

9. Ayonrinde OT, Olynyk JK, Beilin LJ, Mori TA, Pennell CE, de Klerk N et al. Gender-specific differences in adipose distribution and adipocytokines influence adolescent nonalcoholic fatty liver disease. Hepatology. 2011;53(3):800-9. doi: 10.1002/hep.24097. [PubMed: 21374659]

10. Tolman KG, Dalpiaz AS. Treatment of non-alcoholic fatty liver disease. Ther Clin Risk Manag. 2007;3(6):1153-63. [PubMed:18516264]

11. Chalasani N, Younossi Z, Lavine JE, Diehl AM, Brunt EM, Cusi K, et al. The diagnosis and management of non-alcoholic fatty liver disease: practice Guideline by the American Association for the Study of Liver Diseases, American College of Gastroenterology, and the American Gastroenterological Association. Hepatology. 2012;55(6):2005-23. doi:10.1002/hep.25762. [PubMed:22488764]

12. American Gastroenterological A. American Gastroenterological Association medical position statement: nonalcoholic fatty liver disease. Gastroenterology. 2002;123(5):1702-4. [PubMed: 12404244]

13. Zelber-Sagi S, Nitzan-Kaluski D, Goldsmith R, Webb M, Zvibel I Goldiner I, et al. Role of leisure-time physical activity in nonalcoholic fatty liver disease: a population-based study. Hepatology. 2008;48(6):1791-8. doi:10.1002/hep.22525. [PubMed:18972405]

14. Davoodi M, Moosavi H, Nikbakht M. The effect of eight weeks select- 
ed aerobic exercise on liver parenchyma and liver enzymes (AST, ALT) of fat liver patients. J Shahrekord Univ Med Sci. 2012;14(1):84-90.

15. de Piano A, de Mello MT, Sanches Pde L, da Silva PL, Campos RM, Carnier J, et al. Long-term effects of aerobic plus resistance training on the adipokines and neuropeptides in nonalcoholic fatty liver disease obese adolescents. Eur J Gastroenterol Hepatol. 2012;24(11):1313-24. doi: 10.1097/MEG.0b013e32835793ac. [PubMed: 22932160]

16. Haus JM, Solomon TP, Kelly KR, Fealy CE, Kullman EL, Scelsi AR, et al. Improved hepatic lipid composition following short-term exercise in nonalcoholic fatty liver disease. J Clin Endocrinol Metab. 2013;98(7):E1181-8. doi:10.1210/jc.2013-1229. [PubMed: 23616151]

17. Mir A, Aminai M, Marefati $\mathrm{H}$. The impression of aerobic exercises to enzymes measure and liver fat in the man suffering to nonalcoholic fatty liver. Int Res J Appl Basic Sci. 2012;3(9):1897-901.

18. Romijn JA, Pijl H. The muscle-liver axis: does aerobic fitness induce intrahepatic protection against non-alcoholic fatty liver disease? J Physiol. 2009;587(Pt 8):1637. doi: 10.1113/jphysiol.2009.171868. [PubMed: 19369505]

19. Sreenivasa Baba C, Alexander G, Kalyani B, Pandey R, Rastogi S, Pandey A, et al. Effect of exercise and dietary modification on serum aminotransferase levels in patients with nonalcoholic steatohepatitis. J Gastroenterol Hepatol. 2006;21(1 Pt 1):191-8. doi: 10.1111/j.1440-1746.2005.04233.x. [PubMed: 16706832]

20. Di Mauro D, Pagano F, Magaudda L, Speciale F, Speranza G, Bonaiuto $\mathrm{M}$, et al. Aerobic exercise and non-alcoholic fatty liver disease: a case report. J Sports Med Phys Fitness. 2009;49(4):448-52. [PubMed: 20087305]

21. Hallsworth K, Fattakhova G, Hollingsworth KG, Thoma C, Moore S, Taylor R, et al. Resistance exercise reduces liver fat and its mediators in non-alcoholic fatty liver disease independent of weight loss. Gut. 2011;60(9):1278-83. doi: 10.1136/gut.2011.242073. [PubMed: 21708823]

22. Patel NS, Peterson MR, Lin GY, Feldstein A, Schnabl B, Bettencourt $\mathrm{R}$, et al. Insulin Resistance Increases MRI-Estimated Pancreatic Fat in Nonalcoholic Fatty Liver Disease and Normal Controls. Gastroenterol Res Pract. 2013;2013:498296. doi: 10.1155/2013/498296. [PubMed: 24348536]

23. Khalighfard S, Gaeini AA, Nazarali P. Effect of endurance exercise on cardiac marker and exercise-induced immune response. Trauma Mon. 2011;2011(1):45-51.

24. Hopster H, Blokhuis HJ. Validation of a heart-rate monitor for measuring a stress response in dairy cows. Canadian J Anim Sci. 1994;74(3):465-74.

25. Chaudhary S, Kang MK, Sandhu JS. The effects of aerobic versus resistance training on cardiovascular fitness in obese sedentary females. Asian J Sports Med. 2010;1(4):177-84. [PubMed: 22375205]

26. Lira FS, Carnevali LJ, Zanchi NE, Santos RV, Lavoie JM, Seelaender M. Exercise intensity modulation of hepatic lipid metabolism. $J$ Nutr Metab. 2012;2012:809576. doi:10.1155/2012/809576. [PubMed: 22545209]

27. Medicine ACS. ACSM's Guidelines for Exercise Testing and Prescription. Netherlands: Wolters Kluwer Health; 2013.

28. Jackson AS, Pollock ML. Generalized equations for predicting body density of men. Br J Nutr. 1978;40(3):497-504. [PubMed:718832]

29. Iloon Kashkooli R, Najafi SS, Sharif F, Hamedi A, Hoseini Asl MK, Najafi Kalyani M, et al. The effect of berberis vulgaris extract on transaminase activities in non-alcoholic Fatty liver disease. Hepat Mon. 2015;15(2):e25067. doi: 10.5812/hepatmon.25067. [PubMed: 25788958]

30. Gore RM, Levin MS. Textbook of Gastrointestinal Radiology. Philadelphia: Saunders; 2008.

31. Saki F, Karamizadeh Z, Honar N, Moravej H, Ashkani-Esfahani S, Namvar Shooshtarian MH. Association of Plasma Retinol Binding Protein-4 (RBP4) and Sonographic Grading of Fatty Liver in Obese Iranian Children. Hepat Mon. 2012;12(12):e7103. doi:10.5812/ hepatmon.7103. [PubMed: 23423766]

32. Devries MC,Samjoo IA, Hamadeh MJ, Tarnopolsky MA. Effect of endurance exercise on hepatic lipid content, enzymes, and adiposity in men and women. Obesity (Silver Spring). 2008;16(10):2281-8. doi:10.1038/oby.2008.358. [PubMed: 18719669]

33. Matthews DR, Hosker JP, Rudenski AS, Naylor BA, Treacher DF, Turner RC. Homeostasis model assessment: insulin resistance and beta-cell function from fasting plasma glucose and insulin concentrations in man. Diabetologia. 1985;28(7):412-9. [PubMed: 3899825]

34. Willis LH, Slentz CA, Bateman LA, Shields AT, Piner LW, Bales CW, et al. Effects of aerobic and/or resistance training on body mass and fat mass in overweight or obese adults. J Appl Physiol (1985). 2012;113(12):1831-7. doi: 10.1152/japplphysiol.01370.2011. [PubMed: 23019316]

35. van der Heijden GJ, Wang ZJ, Chu ZD, Sauer PJ, Haymond MW, Rodriguez LM, et al. A 12-week aerobic exercise program reduces hepatic fat accumulation and insulin resistance in obese, Hispanic adolescents. Obesity (Silver Spring). 2010;18(2):384-90. doi: 10.1038/oby.2009.274. [PubMed: 19696755]

36. Chen SM, Liu CY, Li SR, Huang HT, Tsai CY, Jou HJ. Effects of therapeutic lifestyle program on ultrasound-diagnosed nonalcoholic fatty liver disease. J Chin Med Assoc. 2008;71(11):551-8. doi:10.1016| S1726-4901(08)70168-0. [PubMed:19015052]

37. Jensen J, Rustad PI, Kolnes AJ, Lai YC. The role of skeletal muscle glycogen breakdown for regulation of insulin sensitivity by exercise. Front Physiol. 2011;2:112. doi: 10.3389/fphys.2011.00112. [PubMed: 22232606]

38. Johnson NA, Sachinwalla T, Walton DW, Smith K, Armstrong A, Thompson MW, et al. Aerobic exercise training reduces hepatic and visceral lipids in obese individuals without weight loss. Hepatology. 2009;50(4):1105-12. doi: 10.1002/hep.23129. [PubMed: 19637289]

39. Davidson LE, Hudson R, Kilpatrick K, Kuk JL, McMillan K, Janiszewski PM, et al. Effects of exercise modality on insulin resistance and functional limitation in older adults: a randomized controlled trial. Arch Intern Med. 2009;169(2):122-31. doi: 10.1001/ archinternmed.2008.558. [PubMed: 19171808]

40. Sigal RJ, Kenny GP, Boule NG, Wells GA, Prud'homme D, Fortier $\mathrm{M}$, et al. Effects of aerobic training, resistance training, or both on glycemic control in type 2 diabetes: a randomized trial. Ann Intern Med. 2007;147(6):357-69. [PubMed:17876019]

41. Castaneda C, Layne JE, Munoz-Orians L, Gordon PL, Walsmith J, Foldvari $\mathrm{M}$, et al. A randomized controlled trial of resistance exercise training to improve glycemic control in older adults with type 2 diabetes. Diabetes Care. 2002;25(12):2335-41. [PubMed: 12453982]

42. Bell LM, Watts K, Siafarikas A, Thompson A, Ratnam N, Bulsara M, et al. Exercise alone reduces insulin resistance in obese children independently of changes in body composition. J Clin Endocrinol Metab. 2007;92(11):4230-5. doi:10.1210/jc.2007-0779. [PubMed: 17698905]

43. Gutin B, Owens S. Role of exercise intervention in improving body fat distribution and risk profile in children. Am J Hum Biol. 1999;11(2):237-47. doi:10.1002/(SICI)1520-6300(1999)11:2<237::AIDAJHB11>3.0.CO;2-9. [PubMed: 11533947]

44. Gutin B, Barbeau P, Owens S, Lemmon CR, Bauman M, Allison J, et al. Effects of exercise intensity on cardiovascular fitness, total body composition, and visceral adiposity of obese adolescents. Am J Clin Nutr. 2002;75(5):818-26. [PubMed: 11976154]

45. Mathieu P, Poirier P, Pibarot P, Lemieux I, Despres JP. Visceral obesity: the link among inflammation, hypertension, and cardiovascular disease. Hypertension. 2009;53(4):577-84. doi: 10.1161/ HYPERTENSIONAHA.108.110320. [PubMed: 19237685]

46. Abangah G, Yousefi A, Asadollahi R, Veisani Y, Rahimifar P, Alizadeh S. Correlation of Body Mass Index and Serum Parameters With Ultrasonographic Grade of Fatty Change in Non-alcoholic Fatty Liver Disease. Iran Red Crescent Med J. 2014;16(1):e12669. doi: 10.5812/ircmj.12669. [PubMed:24719704]

47. Lankarani KB, Ghaffarpasand F, Mahmoodi M, Lotfi M, Zamiri N, Heydari ST, et al. Non alcoholic fatty liver disease in southern Iran: a population based study. Hepat Mon. 2013;13(5):e9248. doi: 10.5812/hepatmon.9248. [PubMed: 23922564]

48. Kodama Y, Ng CS, Wu TT, Ayers GD, Curley SA, Abdalla EK, et al. Comparison of CT methods for determining the fat content of the liver. AJR Am J Roentgenol. 2007;188(5):1307-12. doi: 10.2214/ AJR.06.0992. [PubMed: 17449775]

49. Longo R, Ricci C, Masutti F, Vidimari R, Croce LS, Bercich L, et al Fatty infiltration of the liver. Quantification by $1 \mathrm{H}$ localized magnetic resonance spectroscopy and comparison with computed tomography. Invest Radiol.1993;28(4):297-302. [PubMed: 8478169] 